\title{
EFEKTIVITAS METODE OUTDOOR STUDY DENGAN MUSIK KLASIK TERHADAP KEMAMPUAN MENGANALISIS UNSUR PUISI
}

\author{
Wika Soviana Devi dan Rafvesa Fitria \\ Universitas Muhammadiyah Jakarta \\ Wikasoviana@ymail.com dan Fitriarafvesa@gmail.com
}

\begin{abstract}
Abstrak
Penulisan jurnal ini dilatarbelakangi oleh keinginan penulis untuk mengetahui Efektivitas Metode Outdoor Study dengan Musik Klasik terhadap Kemampuan Menganalisis Unsur Puisi pada siswa kelas X SMA Negeri 87 Jakarta. Metode yang digunakan dalam penelitian ini adalah metode kuantitatif dengan menggunakan True Eksperimental Design. Adapun tujuan penelitian ini adalah untuk mengetahui pengaruh penggunaan metode pembelajaran Outdoor Study dengan musik klasik terhadap kemampuan menganalisis unsur puisi siswa dibandingkan dengan tidak menggunakan metode Outdoor Study dengan Musik Klasik. Penelitian ini dilakukan pada bulan Agustus dengan populasi dalam penelitian ini adalah seluruh siswa kelas X SMA Negeri 87 Jakarta yang berjumlah 215 siswa, sedangkan sampel dalam penelitian ini berjumlah 72 siswa, dengan 36 kelas eksperimen dan 36 kelas kontrol. Setelah divalidasi instrumen didapatkan valid data berdistribusi normal dan homogen. Hasil dari uji hipotesis menunjukan $t_{\text {hitung }}$ sebesar 17,70 lebih besar dari $t_{\text {tabel }}$ sebesar 1,99 ( $t_{\text {hitung }}>t_{\text {tabel }}$ ). Dengan demikian dapat disimpulkan bahwa penggunaan metode Outdoor Study dengan musik klasik terhadap kemampuan menganalisis unsur puisi siswa lebih baik dibandingkan dengan tidak menggunakan metode Outdoor Study dengan musik klasik.
\end{abstract}

Kata Kunci: Outdoor Study, Musik Klasik, Unsur Pembangun Puisi 


\section{PENDAHULUAN}

$\mathrm{K}$

arya sastra pada dasarnya berisi tentang permasalahan dalam kehidupan sosial. Setiap bangsa atau suku bangsa memiliki kehidupan sosial yang berbeda dengan bangsa lain. Sastra terlahir atas hasil karya perilaku manusia dalam kebudayaan yang beraneka ragam seperti suku, ras, agama, maupun tradisi yang berbeda-beda. Keanekaragaman tersebut memiliki ciri khasnya masingmasing dan hal itu memberikan permasalahan dengan pemahaman serta tanggapan yang berbeda juga.

Beberapa contoh karya sastra yang dapat kita lihat adalah cerpen, puisi, novel, drama, film dan banyak lagi karya sastra lain yang dapat kita lihat. Kehadiran karya sastra merupakan manifestasi atas kebudayaan yang ada pada saat itu. Yang dikaitkan dengan pengertian sastra ialah teks-teks yang tidak selalu disusun atau dipakai untuk suatu tujuan komunikatif yang praktis dan yang hanya berlangsung untuk sementara waktu saja. Secara agak dibuat-buat hasil sastra dipergunakan dalam situasi komunikasi yang diatur oleh suatu lingkungan kebudayaan tertentu.

Karya sastra merupakan sebuah bentuk seni yang dituangkan melalui bahasa. Karya sastra terdiri dari beragam bentuk, salah satunya puisi. Sebuah karya sastra dianggap sebagai bentuk ekspresi dari pengarang. Kehidupan sastra lahir karena adanya kegiatan penciptaan atau kegiatan kreatif. Kehidupan sastra ini pun pada hakekatnya terus berkembang, berangsur ke taraf yang lebih tinggi, lebih matang, atau lebih dewasa, baik dalam bentuk pengucapannya maupun dalam "isi”. Melalui karya sastra pengarang dapat dengan bebas berbicara tentang kehidupan yang dialami oleh manusia dengan berbagai

peraturan dan norma-norma dalam interaksinya dengan lingkungan sehingga dalam karya sastra terdapat makna tertentu tentang kehidupan.

Menurut Aminuddin (2011 : 134) puisi berasal dari bahasa Yunani poeima 'membuat' atau poesis 'pembuatan', dan dalam bahasa Inggris disebut poem atau poetry karena lewat puisi pada dasarnya seorang telah menciptakan suatu dunia tersendiri, yang mungkin berisi pesan atau gambaran suasana-suasana tertentu, baik fisik maupun batiniah.

Menurut Pradopo (2014 : 7) menjelaskan puisi itu mengekspresikan pemikiran yang membangkitkan perasaan, yang merangsang imajinasi pancaindra dalam susunan yang berirama. Semua itu merupakan sesuatu yang penting, yang direkam dan diekspresikan, dinyatakan dengan menarik dan memberi kesan. Puisi itu merupakan rekaman dan interpretasi pengalaman manusia yang penting, digubah dalam wujud yang paling berkesan.Dari pendapat diatas dapat disimpulkan bahwa puisi merupakan sebuah karya sastra yang dibuat oleh seseorang berdasarkan suatu imajinasi, pemikiran,atau pun gagasan yang diutarakan melalui tulisan yang indah dan dapat dinikmati oleh semua orang.

Puisi merupakan salah satu karya sastra yang sangat pesat perkembangannya. Setiap puisi memiliki hubungan dengan penyairnya karena puisi tercipta dari pengungkapan diri penyair. Pengkajian sebuah puisi lebih difokuskan pada pengkajian struktur fisik (struktur kebahasaan) dan struktur batin puisinya (perasaan dan suasana jiwa penyair). Medium pengucapan maksud yang hendak disampaikan penyair adalah bahasa. Bahasa 
puisi itu bersifat khas, maka dibutuhkan adanya tipografi yakni bagian dari struktur fisik puisi. Sementara struktur batin puisi mengungkapkan apa yang hendak dikemukakan oleh penyair dengan perasaan dan suasana jiwanya.

Kegiatan pembelajaran puisi, khususnya menganalisis suatu puisi bagi siswa SMA bukan hal yang mudah diajarkan, banyak faktor yang menyebabkan siswa merasa kesulitan dalam menganalisis puisi. Tidak banyak guru yang mempunyai metode atau model untuk melatih peserta didiknya. Dalam strategi belajar mengajar memang sangat dituntut bagi guru untuk menggunakan sebuah metode pembelajaran yang baik dan tepat. Metode yang baik harus memperhatikan siswa, dalam hal ini siswa dijadikan objek yang aktif dalam proses pembelajaran. Salah satu jalan keluarnya yaitu sebuah pembelajaran dengan metode yang menarik dan memancing perhatian siswa.

Pemanfaatan metode pembelajaran yang dikelola guru secara baik dapat membantu siswa memahami materi pelajaran sehingga dapat meningkatkan prestasi belajar siswa. Menerapkan metode pembelajaran yang menarik akan meningkatkan daya imajinasi dan kreatifitas siswa. Metode pembelajaran yang diterapkan harus sesuai dengan materi ajar yang akan disampaikan, yaitu menganalisis unsur pembangun puisi. Untuk merangsang imajinasi dan keinginan siswa dalam menganalisis puisi, maka peneliti menggunakan metode outdoor study dengan musik klasik sebagai metode pembelajaran agar dapat meningkatkan kemampuan dan keinginan siswa dalam menganalisis puisi meningkat sehingga pembelajaran menjadi menyenangkan.
Menurut Husamah (2013 : 19) menjelaskan bahwa proses pembelajaran bisa terjadi dimana saja, di dalam atau pun di luar sekolah. Proses pembelajaran yang dilakukan di luar sekolah, memiliki arti yang sangat penting untuk perkembangan siswa karena proses pembelajaran yang demikian dapat memberikan pengalaman langsung kepada siswa,dan pengalaman langsung memungkinkan materi pelajaran akan semakin konkret dan nyata yang berarti proses pembelajaran akan lebih bermakna.

Metode Outdoor Study adalah metode pembelajaran yang tepat untuk diterapkan pada materi pembelajaran menganalisis unsur puisi, karena metode ini berlangsung di luar kelas yang bertujuan untuk meningkatkan kreatifitas siswa dan imajinasi siswa dalam melaksanakan pembelajaran menganalisis puisi. Menerapkan pembelajaran di luar kelas dapat meningkatkan kreatifitas siswa dalam menuangkan ide dan gagasannya. Melalui penggunaan metode Outdoor Study kemampuan menganalisis unsur puisi siswa dapat lebih meningkat dibandingkan dengan menggunakan metode pembelajaran ceramah.

Musik klasik merupakan sebuah inovasi dalam pembelajaran, karena musik klasik dapat menciptakan suasana belajar terasa santai tetapi siswa tetap siap untuk berkonsentrasi. Disamping itu, musik klasik dapat menimbulkan suasana hati menjadi tenang dan tentram. Dengan ketenangan hati juga konsentrasi, akan membuat siswa mudah menangkap materi dari guru. Penggunaan musik dalam pembelajaran tentunya akan memberikan dampak positif terhadap proses pembelajaran, karena 
musik adalah salah satu cara untuk merangsang pikiran.

Kurikulum 2013 merupakan kurikulum berbasis kompetensi dengan kompetensi dasar (KD) sebagai kompetensi minimal yang harus dicapai oleh peserta didik. Untuk mengetahui ketercapaian KD, guru harus merumuskan sejumlah indikator sebgai acuan penilaian dan sekolah juga harus menentukan ketuntasan belajar minimal atau kritria ketuntasan minimal (KKM) untuk memutuskan seorang peserta didik sudah tuntas atau belum. KKM untuk pelajaran Bahasa Indonesia di SMA 87 Jakarta adalah 75. Maka nilai $\mathrm{C}$ dimulai dari 75. Predikat diatas $\mathrm{C}$ adalah $\mathrm{B}$ dan $\mathrm{A}$.

Penggunaan metode outdoor study dengan musik klasik diharapkan sangat membantu siswa dalam meningkatkan kemampuannya menganalisis unsur puisi. Salah satu upaya untuk mengatasi kesulitan siswa dalam menganalisis unsur puisi adalah dengan mengajak siswa belajar di luar kelas serta memperdengarkan musik klasik yang menenangkan.

\section{METODE PENELITIAN}

$\sqrt{\text { penelitian ini } \begin{array}{l}\text { adalah metode } \\ \text { eksperimen. }\end{array} \text { Penelitian ini }}$ menggunakan True Eksperimental Design. Menurut (Sugiyono, 2015 : 112) dikatakan True Eksperimental Design (eksperimen yang betul-betul), karena dalam desain ini, peneliti dapat mengontrol semua variabel luar yang mempengaruhi jalannya eksperimen.

Dalam desain ini terdapat dua kelompok yang masing-masing dipilih secara random (R). Kelompok pertama diberi perlakuan (X) dan kelompok yang lain tidak. Kelompok yang diberi perlakuan disebut kelompok eksperimen dan kelompok yang tidak diberi perlakuan adalah kelompok kontrol.

Digunakannya metode true experimental design dengan dessain Posttest-Only Control Design dalam penelitian ini, dikarenakan dengan metode ini peneliti dapat mengontrol variabel asing yang mempengaruhi jalannya eksperimen.Selain itu, metode ini digunakan untuk menguji dampak suatu treatment terhadap hasil penelitian, yang dikontrol oleh faktor-faktor lain yang dimungkinkan juga mempengaruhi hasil tersebut.

\section{Desain Posttest-Only Control Design}

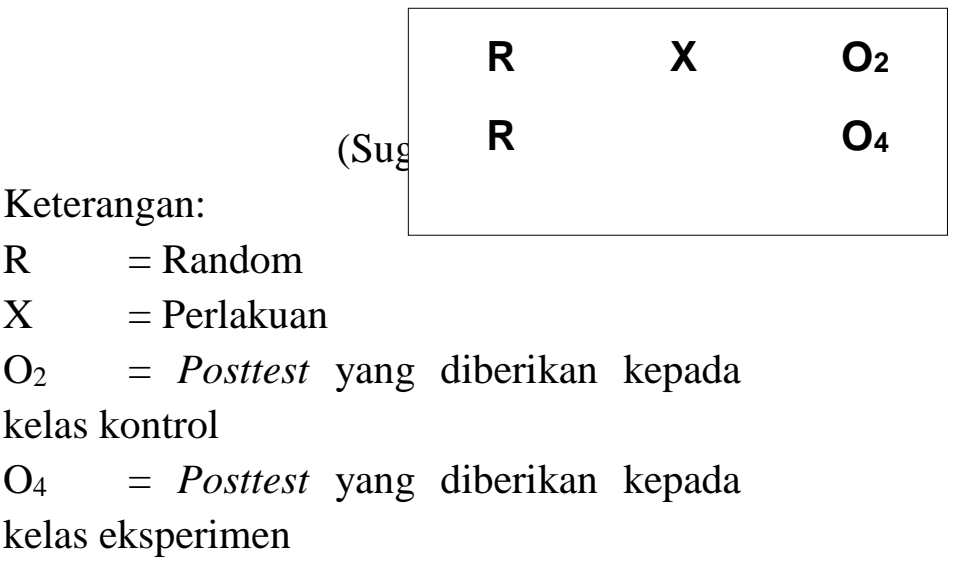

\subsection{Data Hasil Penelitian}

$\mathrm{P}$ enelitian ini dilakukan sebanyak empat pertemuan. Instrumen yang digunakan dalam penelitan ini yaitu instrumen tes yang berupa soal analisis berjumlah 10 soal. Kemudian instrumen tersebut telah di uji validitasnya dengan menggunakan validitas konstruk. Respondan berjumlah 72 siswa dengan 36 siswa kelas eksperimen dan 36 siswa kelas kontrol.Data yang didapat sudah diuji normalitas dan homogenitas.Uji normalitas menggunakan metode chi 
kuadrat dan untuk uji homogenitas menggunakan metode fisher. Berdasarkan data hasil kemampuan analisis unsur-unsur pembangun puisi pada puisi "Batas" yang telah diberikan kepada kelas eksperimen dan kelas control, diperoleh hasil yang berbeda dari masing-masing kelas. Hal tersebut menunjukan bahwa terdapat perbedaan hasil kemampuan analisis unsurunsur pembangun puisi pada puisi "Batas" antara kelas eksperimen dan kelas Kontrol.

Tabel 4.1

Data Hasil kemampuan analisis unsurunsur pembangun puisi pada puisi "Batas"

\begin{tabular}{|c|c|c|}
\hline No. & Kelas Kontrol & $\begin{array}{c}\text { Kelas } \\
\text { Eksperimen }\end{array}$ \\
\hline 1 & 50 & 73 \\
\hline 2 & 51 & 71 \\
\hline 3 & 48 & 62 \\
\hline 4 & 46 & 71 \\
\hline 5 & 55 & 60 \\
\hline 6 & 47 & 52 \\
\hline 7 & 48 & 73 \\
\hline 8 & 47 & 69 \\
\hline 9 & 48 & 68 \\
\hline 10 & 45 & 71 \\
\hline 11 & 47 & 63 \\
\hline 12 & 34 & 62 \\
\hline 13 & 53 & 69 \\
\hline 14 & 53 & 59 \\
\hline 15 & 43 & 67 \\
\hline 16 & 43 & 62 \\
\hline 17 & 48 & 64 \\
\hline 18 & 46 & 70 \\
\hline 19 & 46 & 72 \\
\hline 20 & 49 & 60 \\
\hline 21 & 46 & 70 \\
\hline 22 & 49 & 75 \\
\hline & & \\
\hline
\end{tabular}

\begin{tabular}{|c|c|c|}
\hline 23 & 52 & 68 \\
\hline 24 & 46 & 69 \\
\hline 25 & 43 & 62 \\
\hline 26 & 48 & 61 \\
\hline 27 & 45 & 65 \\
\hline 28 & 51 & 68 \\
\hline 29 & 44 & 70 \\
\hline 30 & 54 & 65 \\
\hline 31 & 54 & 64 \\
\hline 32 & 45 & 62 \\
\hline 33 & 47 & 71 \\
\hline 34 & 45 & 64 \\
\hline 35 & 52 & 64 \\
\hline 36 & 51 & 75 \\
\hline Jumlah & 1719 & 2391 \\
\hline
\end{tabular}

\subsection{Hasil Analisa Data}

Uji coba dilakukan untuk memvalidasi dengan menggunakan teknik validasi konstruk yang diuji oleh validator yaitu ibu Widarti, S.Pd. selaku guru mata pelajaran Bahasa Indonesia kelas XI di SMA Negeri 87 Jakarta.Hasil validasi terdapat 1 butir soal yang harus diperbaiki dari 10 soal. Setelah diperbaiki, 10 butir soal tersebut diujikan kepada siswa di SMA Negeri 87 Jakarta kelas X MIPA-1 dengan jumlah siswa yaitu 36 siswa dan X MIPA-3 dengan jumlah siswa yaitu 36 siswa.

a.

Hasil

\section{Uji Normalitas Data}

Uji normalitas data ini dilakukan untuk mengetahui apakah sampel yang diteliti berasal dari populasi berdistribusi normal atau tidak.Uji normalitas yang digunakan adalah uji chi kuadrat.

Tabel 4.2

Uji Normalitas Kelas Kontrol 
PENA LITERASI : Jurnal PBSI

Volume 1 No. 1 Bulan April Tahun 2018

e-ISSN : 2614-8226

signifikansi $\alpha=0,05$ adalah 11,07 , maka

\begin{tabular}{|c|c|c|c|c|c|c|c|c|c|c|}
\hline $\begin{array}{c}\text { Kelas } \\
\text { Interval }\end{array}$ & $\begin{array}{l}\text { Batas } \\
\text { Kelas }\end{array}$ & $\begin{array}{c}\text { Z- } \\
\text { Score }\end{array}$ & $\begin{array}{l}\text { Luas } \\
0-Z\end{array}$ & $\begin{array}{c}\text { Luas } \\
\mathrm{Z} \\
\text { tabel }\end{array}$ & fe & Fo & $\begin{array}{c}\text { (fo- } \\
\mathrm{fe})^{\wedge} 2 / \mathrm{fe}\end{array}$ & $\mathrm{X}$ & $\mathrm{xf}$ & varians \\
\hline & 33.5 & -0.36 & 0.1255 & & & & & & & \\
\hline $34-37$ & & & & 0.0151 & 0.453 & 1 & 0.660506 & 52.5 & 52.5 & 2756.25 \\
\hline & 37.5 & -0.32 & 0.1406 & & & & & & & \\
\hline $38-41$ & & & & 0.0419 & 1.257 & 0 & 1.257 & 58.5 & 0 & 0.00 \\
\hline & 41.5 & -0.28 & 0.0987 & & & & & & & \\
\hline $42-45$ & & & & 0.0116 & 0.3596 & 8 & 162.3351 & 64.5 & 516 & 338.00 \\
\hline & 45.5 & -0.25 & 0.1103 & & & & & & & \\
\hline $46-49$ & & & & $0.0546^{-}$ & -1.9656 & 16 & -164.206 & 70.5 & 1128 & 4.00 \\
\hline & 49.5 & -0.21 & 0.0557 & & & & & & & \\
\hline $50-53$ & & & & 0.3611 & 10.833 & 8 & 0.740874 & 76.5 & 612 & 242.00 \\
\hline & 53.5 & -0.17 & 0.4168 & & & & & & & \\
\hline $54-57$ & & & & 0.3493 & 11.5269 & 3 & 6.307682 & 82.5 & 247.5 & 396.75 \\
\hline & 56.5 & -0.14 & 0.0675 & & & & & & 2556 & 3737.00 \\
\hline \multicolumn{3}{|c|}{ rata-rata } & \multicolumn{8}{|c|}{71} \\
\hline \multicolumn{3}{|c|}{ varian Total } & \multicolumn{8}{|c|}{103.81} \\
\hline \multicolumn{3}{|c|}{ simpangan baku } & \multicolumn{8}{|c|}{10.19} \\
\hline \multicolumn{3}{|c|}{$\mathrm{x}^{\wedge} 2$ hitung } & \multicolumn{8}{|c|}{7.10} \\
\hline \multicolumn{3}{|c|}{$\mathrm{x}^{\wedge} 2$ tabel } & \multicolumn{8}{|c|}{11.07} \\
\hline \multicolumn{3}{|c|}{ Kesimpulan } & \multicolumn{8}{|c|}{ Data Normal } \\
\hline
\end{tabular}

diperoleh $X_{\text {hitung }}^{2}<X_{\text {tabel }}^{2}$ maka sampel

Berdasarkan tabel diatas dan pada kelas kontrol berdistribusi normal. perhitungan uji normalitas, dengan mean 71,00 dan standar deviasi 10,19 didapat $X_{\text {hitung }}^{2}$ untuk kelas kontrol sebesar 7,10 Tabel 4.3 pada tabel $X_{\text {tabel }}^{2}$ untuk $\mathrm{n}=36$ pada taraf

\section{Uji Normalitas Kelas Eksperimen}


PENA LITERASI : Jurnal PBSI

Volume 1 No. 1 Bulan April Tahun 2018

e-ISSN : 2614-8226

taraf signifikansi $\alpha=0,05$ adalah 11,07 ,

\begin{tabular}{|c|c|c|c|c|c|c|c|c|c|c|}
\hline $\begin{array}{l}\text { Kelas } \\
\text { Interval }\end{array}$ & $\begin{array}{l}\text { Batas } \\
\text { Kelas }\end{array}$ & $\begin{array}{c}\text { Z- } \\
\text { Score }\end{array}$ & $\begin{array}{c}\text { Luas } \\
0-Z\end{array}$ & $\begin{array}{c}\text { Luas } \\
\mathrm{Z} \\
\text { tabel }\end{array}$ & $\mathrm{Fe}$ & Fo & $\begin{array}{c}(\text { fo- } \\
\mathrm{fe})^{\wedge} 2 / \mathrm{fe}\end{array}$ & $\mathrm{X}$ & $\mathrm{xf}$ & varians \\
\hline & 51.5 & -3.21 & 0.002 & & & & & & & \\
\hline $52-55$ & & & & 0.0006 & 0.018 & 1 & 53.57 & 79.5 & 79.5 & 6320.25 \\
\hline & 55.5 & -2.94 & 0.0026 & \multirow{3}{*}{0.0015} & & & & & & \\
\hline \multirow[t]{2}{*}{$56-59$} & & & & & 0.045 & 1 & 20.27 & 85.5 & 85.5 & 177.78 \\
\hline & 59.5 & -2.67 & 0.0082 & & & & & & & \\
\hline \multirow[t]{2}{*}{$60-63$} & & & & 0.0044 & 0.1452 & 9 & -576.00 & 91.5 & 823.5 & 484.00 \\
\hline & 63.5 & -2.40 & 0.0038 & & & & & & & \\
\hline \multirow[t]{2}{*}{$64-67$} & & & & 0.0084 & 0.2772 & 8 & 215.16 & 97.5 & 780 & 14.22 \\
\hline & 67.5 & -2.13 & 0.0166 & & & & & & & \\
\hline \multirow[t]{2}{*}{$68-71$} & & & & 0.0156 & 0.5148 & 12 & 256.24 & 103.5 & 1242 & 261.33 \\
\hline & 71.5 & -1.85 & 0.0322 & & & & & & & \\
\hline \multirow[t]{2}{*}{$72-75$} & & & & 0.0173 & 0.519 & 5 & 38.69 & 109.5 & 547.5 & 568.89 \\
\hline & 74.5 & -1.65 & 0.0495 & & & & & & 3558 & 7826.47 \\
\hline \multicolumn{3}{|c|}{ rata-rata } & \multicolumn{8}{|c|}{98.83} \\
\hline \multicolumn{3}{|c|}{ varian Total } & \multicolumn{8}{|c|}{217.40} \\
\hline \multicolumn{3}{|c|}{ simpangan baku } & \multicolumn{8}{|c|}{14.74} \\
\hline \multicolumn{3}{|c|}{$\mathrm{x}^{\wedge} 2$ hitung } & \multicolumn{8}{|c|}{7.93} \\
\hline \multicolumn{3}{|c|}{$\mathrm{x}^{\wedge} 2$ tabel } & \multicolumn{8}{|c|}{11.07} \\
\hline \multicolumn{3}{|c|}{ Kesimpulan } & \multicolumn{8}{|c|}{ Data Normal } \\
\hline
\end{tabular}

Berdasarkan tabel diatas dan maka diperoleh $X_{\text {hitung }}^{2}<X_{\text {tabel }}^{2}$ maka perhitungan uji normalitas, dengan mean sampel pada kelas eksperimen berdistribusi 98,83 dan standar deviasi 14,74 didapat $X_{\text {hitung }}^{2}$ untuk kelas eksperimen sebesar normal.

7,93 pada tabel $X_{\text {tabel }}^{2}$ untuk $\mathrm{n}=36$ pada 


\section{b. Hasil}

\section{Uji homogenitas Data}

Uji Homogenitas yang digunakan dalam penelitian ini yaitu Uji Fisher. Berikut ini langkah-langkah perhitungannya yaitu :

\section{a. Hipotesis}

$\mathrm{H}_{\mathrm{O}}=\sigma_{1}^{2}=\sigma_{2}^{2}$ (sampel yang dibandingkan mempunyai varians yang homogen) $\mathrm{H}_{\mathrm{a}}=\sigma_{1}^{2} \neq \sigma_{2}^{2}$ (sampel yang dibandingkan mempunyai varians yang tidak homogen)

\section{b. Menentukan Fhitung}

Berdasarkan perhitungan uji normalitas data kelas eksperimen dan kelas kontrol dapat diketahui bahwa varians terbesar adalah varians pada kelas eksperimen dan varians terkecil pada kelas kontrol.

$S_{b}^{2}=53,71$ dan $_{k}^{2}=37,8$

Sehingga $F_{\text {hitung }}=\frac{s_{0}^{n}}{s_{k}^{n}}=\frac{53,71}{37_{e} 8}=1,42$

c.

enggunakan tarif signifikansi $\sigma=5 \%$ atau 0,05

d.

enentukan $\mathrm{F}_{\text {tabel }}$

Menentukan nilai $F_{\text {tabel }}$ mengunakan tabel distribusi pada taraf signifikansi $5 \%$ atau 0,05 dengan rumus $\mathrm{F}_{\text {tabel }}=$

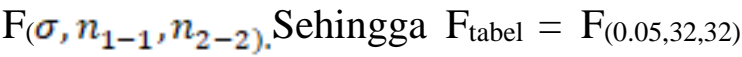
$=1,76$

Tabel 4.4 e. Menentukan

kriteria pengujian $\mathrm{H}_{\mathrm{o}}$

Jika $F_{\text {hitung }} \leq \mathrm{F}_{\text {tabel }}$ maka $\mathrm{H}_{\mathrm{o}}$ diterima dan $\mathrm{H}_{\mathrm{a}}$ ditolak.

Jika $\mathrm{F}_{\text {hitung }}>\mathrm{F}_{\text {tabel }}$ maka $\mathrm{H}_{\mathrm{o}}$ ditolak dan $\mathrm{H}_{\mathrm{a}}$ diterima.

f. Membandingkan dan menyimpulkan

Berdasarkan hasil perhitungan diatas untuk $\sigma=0,05$ diperoleh $F_{\text {hitung }} \leq F_{\text {tabel }}=1,42 \leq 1,76$, maka dapat disimpulkan bahwa populasi dari kedua kelas yaitu kelas eksperimen dan kelas kontrol memiliki varians yang sama atau homogen. Sehingga pengujian dapat dilanjutkan menggunakan uji-t yang homogen.

\section{c. Hasil Uji Hipotesis Penelitian}

Berdasarkan perhitungan yang telah dilakukan pada uji normalitas dan homogenitas maka diperoleh data kelas eksperimen dAk kelas kontrol berdistribusi normal dan populasi yang homogen. Sehingga pengujian hipotesis menggunakan uji-t dengan rumus dan langkah-langkah sebagai berikukI:

a. Hipotesis model statistika

$\mathrm{H}_{\mathrm{o}}: \mu_{1} \leq \mu_{2}$

Keterangan:

$\mu_{1}$ : Rata-rata nilai analisis belajar unsurunsur pembangun puisi siswa kelas eksperimen

Perhitungan Uji Homogenitas

\begin{tabular}{|c|c|c|c|}
\hline Statistika & $\begin{array}{c}\text { Kelas } \\
\text { Kontrol }\end{array}$ & $\begin{array}{r}\text { Kelas } \quad \mu_{2} \\
\text { Eksperimenuns }\end{array}$ & $\begin{array}{l}\text { : Rata-rata nilai analisis belajar unsur- } \\
\text { sur pembangun puisi siswa kelas kontrol }\end{array}$ \\
\hline Varians & 37.8 & 53.71 & \multirow{4}{*}{$\begin{array}{c}\text { b. Perhitungan } \\
\text { menggunakan Excel } \\
\text { Tabel 4.5 Perhitungan Uji Hipotesis }\end{array}$} \\
\hline f.hitung & \multicolumn{2}{|c|}{1.42} & \\
\hline f.tabel & \multicolumn{2}{|c|}{1.76} & \\
\hline Kesimpulan & \multicolumn{2}{|c|}{ Ho diterima dan Ha ditolak } & \\
\hline
\end{tabular}




\begin{tabular}{|l|r|c|}
\hline Statistik & $\begin{array}{l}\text { Kelas } \\
\text { Kontrol }\end{array}$ & Kelas Eksperimen \\
\hline Rata-rata & 71 & 98.83 \\
\hline Varians & 37.8 & 53.71 \\
\hline S gab & \multicolumn{2}{|c|}{6.67} \\
\hline t.hitung & \multicolumn{2}{|c|}{17.70} \\
\hline t.tabel & \multicolumn{2}{|c|}{ pengujian } \\
\hline Kesimpulan & \multicolumn{2}{|c|}{ Ho ditolak dan Ha diterima } \\
\hline \multicolumn{3}{|c|}{ c. Kriteria } \\
& \multicolumn{2}{|c|}{ hipotesis }
\end{tabular}

Jika $t_{\text {hitung }} \leq \mathrm{t}_{\text {tabel }}$ maka $\mathrm{H}_{\mathrm{o}}$ diterima dan $\mathrm{H}_{\mathrm{a}}$ ditolak.

Jika thitung $>t_{\text {tabel }}$ maka $\mathrm{H}_{\mathrm{o}}$ ditolak dan $\mathrm{H}_{\mathrm{a}}$ diterima.

\section{d. Kesimpulan}

Berdasarkan data diatas diperoleh $t_{\text {hitung }}>t_{\text {tabel }}$ karena 17,70 $>1,99$ sehingga kriteria pengujian hipotesis penelitian ini dinyatakan $\mathrm{H}_{\mathrm{o}}$ ditolak dan $\mathrm{H}_{\mathrm{a}}$ diterima dengan demikian berarti hasil kemampuan analisis unsur-unsur pembangun puisi pada puisi "Batas" lebih baik di bandingkan dengan tidak menggunakan metode Outdoor Study dengan musik klasik.

Pada dasarnya siswa kelas X SMA Negeri 87 Jakarta mempunyai tingkat pemahaman terhadap pelajaran Bahasa Indonesia dengan cukup baik serta didukung dengan sikap santun mereka selama proses pembelajaran. Ini yang ditemukan peneliti selama melakukan proses penelitian di sekolah tersebut. Ketika peneliti melakukan terobosan dengan metode Outdoor Study dengan musik klasik berdampak bagi siswa dimana memberikan perubahan yang berarti bagi siswa, terutama dalam kemampuan menganalisis unsur-unsur pembangun puisi. Proses pembelajaran untuk siswa harus benar-benar menyenangkan, sehingga siswa betah untuk belajar. Suasana pembelajaran diciptakan agar tidak ada penekanan psikologis antara guru dan siswa. Pembelajaran di luar kelas (Outdoor Study) merupakan salah satu upaya terciptanya pembelajaran yang terhindar dari kejenuhan, kebosanan, dan persepsi belajar hanya di dalam kelas. Dengan belajar di luar kelas akan tercipta suasana pembelajaran yang santai dan juga sejuk. Apalagi dengan menyalakan musik klasik untuk diperdengarkan kepada siswa selama menganalisis unsur-unsur pembangun suatu puisi. Ini akan membuat daya konsentrasi dan imajinasi anak dalam menganalisis unsur-unsur puisi meningkat. Sebab musik klasik itu sendiri mampu meningkatkan kecerdasan otak anak.

Proses pembelajaran ini diawali dengan peneliti menyampaikan tujuan pembelajaran secara lisan di dalam kelas, lalu peneliti menyampaikan judul materi yang akan dipelajari serta menjelaskan singkat defenisi puisi dan unsur-unsur pembangun puisi di dalam kelas. Selanjutnya, peneliti mengajak siswa keluar kelas dengan tertib.Peneliti menentukan lokasi yang nyaman untuk siswa (tetap di dalam lingkungan sekolah) agar siswa mampu menganalisis unsur-unsur pembangun puisi dengan tenang tapi santai serta lokasi yang tidak terlalu bising agar musik klasik bisa diperdengarkan. Setelah siswa merasa nyaman dengan lokasi yang ditentukan, peneliti menanyakan apakah siswa sudah siap untuk menganalisis unsurunsur pembangun puisi. Kemudian, peneliti memberikan siswa masing-masing satu puisi untuk dianalisis yaitu puisi "Batas" yang terdapat pada kumpulan puisi "Tidak Ada New York Hari Ini” karya M. Aan,Mansur. Peneliti memperdengarkan musik klasik, dan mengamati siswa. 


\section{Dari hasil penelitian peneliti}

di lapangan terbukti bahwa penggunaan metode Outdor Study dengan musik klasik berpengaruh terhadap kemampuan menganalisis unsur-unsur pembangun puisi pada siswa. Sebagaimana yang telah dikemukakan oleh Husamah bahwasanya metode Outdoor Study ini memberikan alternatif cara pembelajaran mata pelajaran Bahasa Indonesia dengan cara membangun makna atau dengan melibatkan lebih banyak indera penglihatan, indera penciuman pada siswa dan memberikan pengalaman yang lebih berkesan (karena mengalami sendiri) tentang materi pelajaran. Hal ini berdasarkan $\mathrm{H}_{\mathrm{o}}$ ditolakdan hipotesis $\mathrm{H}_{\mathrm{a}}$ diterima, artinya rata-rata kemampuan menganalisis unsur-unsur pembangun puisi pada siswa kelas eksperimen lebih baik daripada rata-rata kemampuan menganalisis unsur-unsur pembangun puisi pada siswa kelas kontrol.

\section{KESIMPULAN}

$\mathrm{B}$ erdasarkan temuan penelitian serta pembahasan yang dikemukakan sebelumnya, diperoleh kesimpulan sebagaiberikut :

Penerapan metode Outdoor Study dengan music klasik merupakan metode dimana peneliti menyampaikan tujuan pembelajaran secara lisan di dalam kelas, lalu peneliti menyampaikan judul materi yang akan dipelajari serta menjelaskan singkat defenisi puisi dan unsur-unsur pembangun puisi di dalam kelas. Selanjutnya, peneliti mengajak siswa keluar kelas dengan tertib. Peneliti menentukan lokasi yang nyaman untuk siswa (tetap di dalam lingkungan sekolah) agar siswa mampu menganalisis unsur-unsur pembangun puisi dengan tenang tapi santai serta lokasi yang tidak terlalu bising agar musik klasik bias diperdengarkan. Setelah siswa merasa nyaman dengan lokasi yang ditentukan, peneliti menanyakan apakah siswa sudah siap untuk menganalisis unsurunsur pembangun puisi. Kemudian, peneliti memberikan siswa masing-masing satu puisi untuk dianalisis yaitu puisi "Batas" yang terdapat pada kumpulan puisi "Tidak Ada New York Hari Ini" karya M. Aan Mansur. Peneliti memperdengarkan music klasik, dan mengamati siswa.

Implementasi metode Outdoor Study dengan musikklasik terhadap kemampuan menganalisis unsurunsur pembangun puisi pada puisi "Batas" siswa kelas X MIPA-3 di SMA Negeri 87 Jakarta lebih baik dibandingkan dengan tidak menggunakan metode Outdoor Study dengan musik klasik terhadap kemampuan menganalisis unsur-unsur pembangun puisi pada siswa. Terbukti uji statistika yang dimana $t_{\text {hitung }}>t_{\text {tabel }}$ karena $17,70>1,99$ sehingga criteria pengujian hipotesis penelitian ini dinyatakan $\mathrm{H}_{\mathrm{o}}$ ditolak dan $\mathrm{H}_{\mathrm{a}}$ diterima.

\section{DAFTAR PUSTAKA}

Aminuddin. 2011. Pengantar Apresiasi Karya Sastra. Bandung: Sinar Baru

Algensindo.

Arifin.Zainal.2011.Evaluasi

Pembelajaran.Bandung:PT Remaja

Rosdakarya

Arikunto, Suharsimi.2013.Prosedur penelitian Suatu pendekatan Praktik.Jakarta:Rineka Cipta 
PENA LITERASI : Jurnal PBSI

Volume 1 No. 1 Bulan April Tahun 2018

e-ISSN : 2614-8226

Campbell, Linda.2005.Metode

Pembelajaran.Depok:Intuisi Press

Faizi, Mastur. 2013.Ragam

Metode

Mengajarkan Eksakta Pada

Murid.Jogjakarta:Diva Press

Heryatni, Henny.2004. "Gambaran

Kepribadian Dari Penikmat Musik Klasik, Jazz, dan Dangdut'. Skripsi. Depok:

Fakultas Psikologi, Universitas Indonesia

Husamah.2013.Outdoor

Learning.Jakarta:Prestasi Pustaka

Kadir.2015. Statistika Terapan.

Jakarta:Prestasi Pustaka

Kosasih, E.2008.Apresiasi Sastra Indonesia.Jakarta:Nobel Edumedia.

Mansur,Aan.2016.Tidak Ada New York Hari Ini.Jakarta:Gramedia Pustaka Utama

Margono,S.2010.Metodologi Penelitian

Pendidikan.Jakarta:Rineka Cipta

Mulyadi,dkk.2016.Intisari

Sastra

Indonesia.Bandung:Yrama Widya

Musbikin,Imam.2009.Kehebatan musik untuk mengasah kecerdasan anak.Jogjakarta:Power Books (IHDINA).

Muttaqin, Moh. 2008. Seni Musik Klasik. Jakarta:Departemen Pendidikan Nasional

Nurgiyantoro,Burhan.2010.Penilaian

Pembelajaran Bahasa.

Yogyakarta:BPFE
Pradopo, Rachmat Djoko.2014.Pengkajian

Puisi.Yogyakarta:Gadjah Mada

University Press.

Siregar,Syofian.2013.Metode Penelitian Kuantitatif.Jakarta:PT Fajar Interpratama Mandiri

Sugiyono.2015.Metode

Penelitian

Kuantitatif,Kualitataif,

dan

$R \& D$.Bandung:Alfabeta

Sundayana,Rostiana.2014.Statistika

Penelitian Pendidikan. Bandung:Alfabeta

Tim Ilmu Bahasa.2016.Rangkuman

Pembahasan

Sastra

Indonesia.Pamulang:Ilmu Bumi Pamulang

Yamin,Martinis.2013.Strategi dan Metode Dalam Mosel Pembelajaran.Jakarta:GP

Press

Vera, Adelia.2012.Metode Mengajar Anak Di Luar Kelas (Outdoor Study).Jogjakarta:Diva Press

Widyastari, Marini.2002."Sosialisasi Musik Klasik Pemain Orkestra UI "Mahawaditra"”, Skripsi. Depok: Fakultas Ilmu-Ilmu Sosial dan Ilmu Politik, Universitas Indonesia. 